\title{
Expression of cytoskeletal proteins during the course of experimental diabetic nephropathy
}

\author{
T. Sanai, T. Sobka, T. Johnson, M.El-Essawy, E. C. Muchaneta-Kubara, O. Ben Gharbia, S. Oldroyd, A. M. El Nahas
}

Sheffield Kidney Institute, Northern General Hospital Trust, Sheffield, UK

\section{Abstract}

Aims/hypothesis: Diabetic nephropathy is characterised by structural changes known to be associated in non-diabetic nephropathies with the expression of the cytoskeletal proteins a-smooth muscle actin and vimentin. We aimed to investigate the expression of cytoskeletal proteins in experimental diabetic nephropathy.

Methods. Rats were made diabetic by an injection of streptozotocin $(45 \mathrm{mg} / \mathrm{kg})$. Groups of rats $(n=6)$ and their respective controls $(n=4)$ were killed at different time intervals. (days 7, 15, 30, 60, 90 and 120). We also studied two groups of diabetic rats treated with a long-acting insulin; the first $(n=8)$ was treated from the induction of diabetes and the second $(n=8)$ received insulin from day 15 onward. At each time-point, kidney function, proteinuria and histology were evaluated. Cytoskeletal proteins and collagens III and IV deposition was determined by immunohistochemistry. Changes in the transcription of the cytoskeletal proteins was determined by northern blot analysis.

Results. Although normal glomeruli did not express $\alpha$ smooth muscle actin until late in the time course, it was detected in diabetic mesangium from day 7 onward. In the interstitium, it appeared in a perivascular and peritubular distribution. Vimentin was detectable within normal glomerular epithelial cells and increased rapidly (days 7 and 15) in diabetic rats. Vimentin also appeared early within the lining of the peritubular capillaries and damaged diabetic tubules. These changes were associated with a delayed increased transcription of $\alpha$-smooth muscle actin and vimentin. Treatment with insulin (early or late) attenuated and reversed respectively the expression of cytoskeletal proteins and collagens within diabetic kidneys. Close correlations were noted between the number of $\alpha$-smooth muscle actin positive cells within diabetic glomeruli and mesangial expansion $(r=0.46, p<0.02)$ as well as interstitial $\alpha$-smooth muscle actin positive cells and interstitial fibrosis $(r=0.51, p<0.002)$.

Conclusion/interpretation. Changes in the expression of cytoskeletal proteins within the kidneys of diabetic rats suggest a role for $\alpha$-smooth muscle actin and vimentin in the pathogenesis of diabetic kidney disease. [Diabetologia (2000) 43:91-100]

Keywords Diabetic nephropathy, cytoskeletal proteins, $\alpha$-smooth muscle actin, vimentin.
Diabetic nephropathy is rapidly becoming the most common cause of end-stage renal failure in the world. Its progression is associated with renal structural and

Received: 28 April 1999 and in revised form: 4 July 1999

Corresponding author: Professor A.M.El Nahas, Sheffield Kidney Institute, Northern General Hospital Trust, Herries Road, Sheffield S5 7AU, UK

Abbreviations: $\alpha$-SMA, $\alpha$-Smooth muscle actin; STZ, streptozotocin. functional changes. Structurally, renal hypertrophy is often associated with glomerular mesangium expansion and increase in proximal tubular size [1]. These changes have been linked to the early diabetic renal hyperfunction implicated in the initiation and progression of the nephropathy [2]. Tubular changes also involve vacuolation and lipidosis [3]. Ultimately, the progression of renal failure and the associated hypertension are associated with glomerular and vascular hyalinosis as well as interstitial fibrosis. The latter 
is believed to play an important role in diabetic renal dysfunction [4].

Many of the structural changes observed in diabetic nephropathy are shared with other chronic nephropathies. In these, mesangial cell proliferation/activation, tubular damage and regeneration as well as interstitial fibrosis have been associated with the neoexpression of a wide range of cytoskeletal proteins including $\alpha$-smooth muscle actin $\alpha$-SMA and the intermediate filament protein vimentin [5]. Alphasmooth muscle actin is expressed within proliferating or activated mesangial cells $[6,7]$. Tubular damage and regeneration on the other hand lead to the appearance of vimentin [5]. Interstitial fibrosis has been attributed to the proliferation of activated fibroblasts expressing $\alpha$-SMA; the myofibroblasts [5].

Whether the renal structural changes observed in experimental diabetes mellitus are associated with the expression of cytoskeletal proteins was investigated in this study.

\section{Material and methods}

Animals. Male Wistar rats 10 to 12 weeks of age and weighing $300 \mathrm{~g}$ to $350 \mathrm{~g}$ (Sheffield University strain) were used. These animals were housed two or three to a cage at a constant temperature $\left(18^{\circ} \mathrm{C}\right)$ and humidity $(45 \%)$ on a 12-h light/dark cycle. They had free access to standard laboratory rat chow (Labsure, March, Cambridge) and to tap water. All the experiments were carried out according to the rules and regulations laid down by the Home Office (Animal Scientific Procedure Act 1986, UK).

Experimental protocol. Diabetes mellitus was induced in Wistar rats by a single intravenous injection of streptozotocin (STZ; $60 \mathrm{mg} / \mathrm{kg}$ of body weight). Controls were injected with the citrate buffer. Groups of six diabetic and four control rats were killed at 7, 15, 30, 60, 90 and 120 days after the injection of STZ. An additional two groups of diabetic rats $(n=16)$ were treated with a long-acting insulin; Lente insulin (CP pharmaceuticals, Wrexham, Wales) with doses ranging from 5 to 30 units per $24 \mathrm{~h}$ by intraperitoneal injection. Serum blood glucose was measured $24 \mathrm{~h}$ after insulin treatment. Insulin was titrated using a combination of urine and serum glucose concentrations; the first group $(n=8)$ had the insulin treatment initiated early; within $24 \mathrm{~h}$ of the induction of diabetes. This group was planned to determine whether the prevention of hyperglycaemia would prevent the anticipated changes in the expression of cytoskeletal proteins. The second group of diabetic rats $(n=8)$ had the insulin treatment initiated late; 15 days after the onset of diabetes. This was planned to examine the reversibility of the observed changes. Day 15 was chosen based on preliminary experiments suggesting an early peak (around day 7 to 14) in glomerular expression of $\alpha$ SMA and vimentin. Insulin treated groups of rats were killed 2 weeks after the initiation of insulin $(n=4)$ and on day 120 $(n=4)$.

At each point interval, rats' serum creatinine and glucose, systolic blood pressure as well as 24-h urinary protein excretion were measured. Urine analysis for glucose and ketones was undertaken within $24 \mathrm{~h}$ of the induction of diabetes using Multistix (Bayer Diagnostics, Newsbury, UK). Systolic blood pressure was measured in anaesthetised rats by a tailcuff plethysmography method (Harvard Instruments, Kent, UK). Proteinuria was measured according to the Biuret method. Serum creatinine and glucose were measured by standard autoanalyser technique (Monarch 2000, Monmouth, UK).

At the time of killing, the rats were deeply anaesthetised and had their body and kidney weights estimated. Fractional kidney weight was calculated by dividing the kidney weight by the body weight. For histological evaluation, 2-4 mm thick slices were fixed in formal-calcium ( $4 \%$ paraformaldehyde and $2 \%$ calcium chloride, $\mathrm{pH} 7.4$ ) and paraffin-embedded for histological and immunocytochemical examination. For mRNA analysis, one quarter of a kidney (cut sagittally to be representative of all kidney compartments) was snap frozen and stored in liquid nitrogen until analysis.

Immunohistochemistry. Kidney tissue was fixed with formalcalcium ( $\mathrm{pH} 7.4$ ), overnight, $4^{\circ} \mathrm{C}$. Tissues were subsequently embedded in paraffin wax, sectioned at $4 \mu \mathrm{m}$ and the sections mounted on gelatinised slides. Dewaxed, hydrated sections were processed after microwave treatment and stained as described previously $[8,9]$. Subsequently, sections were incubated with the primary antibody diluted with phosphate buffered saline (PBS)/bovine serum albumin (BSA) overnight $\left(4^{\circ} \mathrm{C}\right.$, in a humid atmosphere). Thereafter, the sections were treated using an avidin-biotin peroxidase procedure (Vector ABC Elite staining kit, Vector Laboratories, Peterborough, UK) with 3amino 9 ethyl-carbazole as substrate (giving a red end colour) (AEC substrate kit, Vector Laboratories, UK), counterstained with dilute haematoxylin (Shandon, Southern Runcorn, UK) and mounted with an aqueous mounting medium, (Glycergel, Dako Patts, High Wycombe, UK). Both qualitative and quantitative assessment of the immunostain was undertaken (see below).

Control sections were incubated with the non-immune corresponding immunoglobulin (mouse or goat) (Dako Patts) or processed after the omission of the primary antibody.

Antibodies. The anti-cytoskeletal proteins antibodies used were of known and proven specificity; a specific monoclonal anti-SMA1 antibody supplied to us by Professor G. Gabbiani (University of Geneva, Switzerland) [10]. Monoclonal mouse anti-swine vimentin (Dako, Cambridge, UK) [11]. Polyclonal goat anti-human collagen III and IV antibodies (Southern Biotechnology, Birmingham, Ala., USA) [8].

Quantitative assessment of renal fibrosis and immunohistochemical staining. The extent of renal fibrosis (mesangial and tubulointerstitial expansion) after the induction of diabetes was determined by two of the authors (T. Sanai and S. Oldroyd) blindly, using morphometric analysis based on point counting procedures to measure volume densities $(\mathrm{Vv})$ [12-14]. For this, dewaxed sections stained with periodic acid Schiff (PAS) (for glomerular mesangial changes) or Masson's trichrome stain (for interstitial changes) were used. Transverse sections of the kidney which passed through the papilla were selected. These were viewed down a light microscope with $\mathrm{a} \times 40$ flat field objective. A squared lattice of 64 or 25 points (for glomerular and tubulointerstitial counting respectively) with a surface area of $0.016 \mathrm{~mm}^{2}$ was superimposed to the tissue via a drawing tube and the data collected from a minimum of 25 glomeruli or a series of adjacent fields extending perpendicularly from the cortex to the junction between the outer and inner stripe of the outer medulla. Three such linear series of 9 to 12 fields were measured per section and two stained sections per kidney analysed [14]. 
Table 1. Clinical and renal characteristics of control and diabetic rats (Means \pm SD)

\begin{tabular}{|c|c|c|c|c|c|c|}
\hline Days & Groups & $\begin{array}{l}\text { Body weight } \\
\text { (grams) }\end{array}$ & $\begin{array}{l}\text { Kidney } \\
\text { weight } \\
(\mathrm{mg})\end{array}$ & $\begin{array}{l}\text { Fractional } \\
\text { kidney } \\
\text { weight } \times 10^{3}\end{array}$ & $\begin{array}{l}\text { S Creatinine } \\
\mu \mathrm{mol} / 1\end{array}$ & $\begin{array}{l}\text { Proteinuria } \\
\mathrm{mg} / 24 \mathrm{~h}\end{array}$ \\
\hline 7 & $\begin{array}{l}\text { Sham } \\
\text { Diabetic }\end{array}$ & $\begin{array}{c}437 \pm 24.0 \\
376.3 \pm 10.0^{\mathrm{a}}\end{array}$ & $\begin{array}{l}1.19 \pm 0.1 \\
1.42 \pm 0.1^{\mathrm{a}}\end{array}$ & $\begin{array}{l}2.6 \pm 0.2 \\
3.8 \pm 0.1^{\mathrm{a}}\end{array}$ & $\begin{array}{l}51.7 \pm 9.1 \\
42.2 \pm 8.9\end{array}$ & $\begin{array}{l}14.6 \pm 4.6 \\
52.8 \pm 9.5^{\mathrm{b}}\end{array}$ \\
\hline 15 & $\begin{array}{l}\text { Sham } \\
\text { Diabetic }\end{array}$ & $\begin{array}{l}423.7 \pm 12.3 \\
354.2 \pm 23.4^{b}\end{array}$ & $\begin{array}{l}1.14 \pm 0.1 \\
1.53 \pm 0.2^{b}\end{array}$ & $\begin{array}{l}2.7 \pm 0.2 \\
4.3 \pm 0.4^{\mathrm{b}}\end{array}$ & $\begin{array}{l}38.0 \pm 4 \\
34.8 \pm 3.4\end{array}$ & $\begin{array}{l}16.8 \pm 2.1 \\
92.8 \pm 36.0^{c}\end{array}$ \\
\hline 60 & $\begin{array}{l}\text { Sham } \\
\text { Diabetic }\end{array}$ & $\begin{array}{l}525.0 \pm 14.1 \\
359.4 \pm 46.5^{b}\end{array}$ & $\begin{array}{l}1.3 \pm 0.1 \\
1.8 \pm 0.2^{b}\end{array}$ & $\begin{array}{l}2.6 \pm 0.2 \\
5.1 \pm 0.2^{c}\end{array}$ & $\begin{array}{l}37.2 \pm 2.6 \\
32.0 \pm 2.0\end{array}$ & $\begin{array}{r}13.2 \pm 0.2 \\
124.4 \pm 28^{c}\end{array}$ \\
\hline 90 & $\begin{array}{l}\text { Sham } \\
\text { Diabetic }\end{array}$ & $\begin{array}{l}485.6 \pm 26.1 \\
352.2 \pm 66.4^{b}\end{array}$ & $\begin{array}{l}1.1 \pm 0.1 \\
1.5 \pm 0.2^{b}\end{array}$ & $\begin{array}{l}2.2 \pm 0.1 \\
4.6 \pm 1.1^{b}\end{array}$ & $\begin{array}{l}44.8 \pm 1.4 \\
42.0 \pm 2.0\end{array}$ & $\begin{array}{c}15.8 \pm 3 \\
179.0 \pm 22^{c}\end{array}$ \\
\hline 120 & $\begin{array}{l}\text { Sham } \\
\text { Diabetic }\end{array}$ & $\begin{array}{l}520.8 \pm 24.6 \\
314.8 \pm 30.2^{b}\end{array}$ & $\begin{array}{l}1.4 \pm 0.1 \\
1.6 \pm 0.2\end{array}$ & $\begin{array}{l}5.1 \pm 0.8 \\
9.2 \pm 1.3^{\mathrm{b}}\end{array}$ & $\begin{array}{l}35.4 \pm 3.9 \\
30.0 \pm 2.0\end{array}$ & $\begin{array}{l}18.3 \pm 3 \\
168 \pm 0.3^{c}\end{array}$ \\
\hline 30 & $\begin{array}{l}\text { Insulin } \\
\text { Late }\end{array}$ & $444.8 \pm 42.7$ & $1.5 \pm 0.1$ & $3.3 \pm 0.1$ & $39 \pm 7.6$ & $17.3 \pm 1.5^{\mathrm{f}}$ \\
\hline 120 & & $439.1 \pm 12.4$ & $2.3 \pm 0.2$ & $5.4 \pm 0.3$ & $42.9 \pm 4.5^{\mathrm{d}}$ & $36 \pm 12^{f}$ \\
\hline
\end{tabular}

Insulin Early refers to the group of rats where insulin treatment started within 24 hours from onset of diabetes. Insulin Late refers to insulin treatment started 15 days after the onset of diabetes.
${ }^{\mathrm{a}}=p<0.05,{ }^{\mathrm{b}}=p<0.01,{ }^{\mathrm{c}}=p<0.001$ untreated diabetic compared to Sham-treated rat. ${ }^{\mathrm{d}}=p<0.05,{ }^{\mathrm{e}}=p<0.01,{ }^{\mathrm{f}}=$ $p<0.001$ insulin-treated compared with untreated diabetic rats
For the evaluation of the distribution of the immunohistochemical staining, two of the authors (T. Sanai and E. C. Muchaneta-Kubara) applied the same point counting method as detailed above using a squared lattice 25 points (for interstitial and vascular immunostain quantification) and 64 points (for glomerular staining)].

The percentage points falling on stained structures was estimated in relation to the total number of points counted.

Quantitative analysis of $m R N A$. Alpha actin and vimentin mRNA expressions were determined by northern blot analysis. Total RNA was extracted using Trizol (Gibco-BRL, Paisley, UK) and quantified by both optical density at $260 \mathrm{~nm}$ and UV densitometry of the $18 \mathrm{~s}$ rRNA subunit. Then $15 \mu \mathrm{g}$ of total RNA was run on a $1.2 \%(w / v)$ Agarose / MOPS / formaldehyde gel and capillary blotted onto Hybond N (Amersham, Amersham, UK) and cross-linked with $70 \mathrm{~mJ} / \mathrm{cm}^{2} \mathrm{UV}$ radiation (UV crosslinker, Amersham, UK). This was then probed with ${ }^{32} \mathrm{P}$ dCTP random primed DNA probes (Prime a gene, Promega, Southampton, UK) specific for alpha actin and vimentin. The alpha actin probe was generated from a $431 \mathrm{bp}$ PCR product of alpha actin (EMBL accession number X06801)[15] covering base pairs 210 to 623 and was a kind gift from C. Grupp (Georg-August-University, Goettingen, Germany). The vimentin probe was prepared from a 1852 base pair vimentin cDNA (EMBL accession number Z19554) [16] that was a kind gift from H. Herrmann (German Cancer Research Centre, Cellbiology, Heidelberg, Germany). Probed membranes were then exposed to Biomax MS film (Sigma, Poole, UK) for up to $16 \mathrm{~h}$ for vimentin and $8 \mathrm{~h}$ for alpha actin. The resulting autoradiograph was then quantified by scanning densitometry using a Bio-Rad GS-690 densitometer and Molecular Analyst version 4 software (Bio-Rad, Hertfordshire, UK). Transcript size was determined by comparison to RNA molecular weight markers (Promega, UK) using the same analysis package. Values were then corrected for loading using repeat probings with the housekeeping gene cyclophilin and the $18 \mathrm{~s}$ ribosomal RNA (rRNA) subunit on ethidium bromide stained gels. The cyclophilin probe used was a 994 bp complete DNA sequence of the human cyclophilin (liver isoform). In rat kidneys, this probe binds to a single $1.9 \mathrm{~kb}$ transcript. It was supplied to us courtesy of Dr D.J. Bergsma of SmithKline and Beecham (King of Prussia, Pa., USA).

Statistical analysis. Results are expressed as mean and standard deviations (mean $\pm \mathrm{SD}$ ). Sets of results were compared using a one-way analysis of variance (ANOVA) routine with Bonferroni correction for multiple comparisons. Note northern blots were tested by doing a single test (one-way unequal variance) at each time point. Hence results are represented as per cent increase over controls. In all statistical tests, a probability value of less than 0.05 was taken as significant.

\section{Results}

General observations. Most rats injected with STZ developed diabetes with a serum glucose ranging from $28 \mathrm{mmol} / \mathrm{l}$ to $36 \mathrm{mmol} / \mathrm{l}(31.5 \pm 3.3 \mathrm{mmol} / \mathrm{l})$. The serum glucose concentrations of normal rats were around a median of $10.5 \mathrm{mmol} / \mathrm{l}$. Only one rat failed to develop diabetes (it was used as control for the effect of STZ on the expression of immunoreactive cytoskeletal proteins and collagens). Rats treated with insulin had a range of serum glycaemia from 9.9 to $16 \mathrm{mmol} / \mathrm{l}$. Whereas this was achieved with a range 
Table 2. Histological and immunohistochemical scarring variables (percentage (\%) of positive counted points; Means \pm SD)

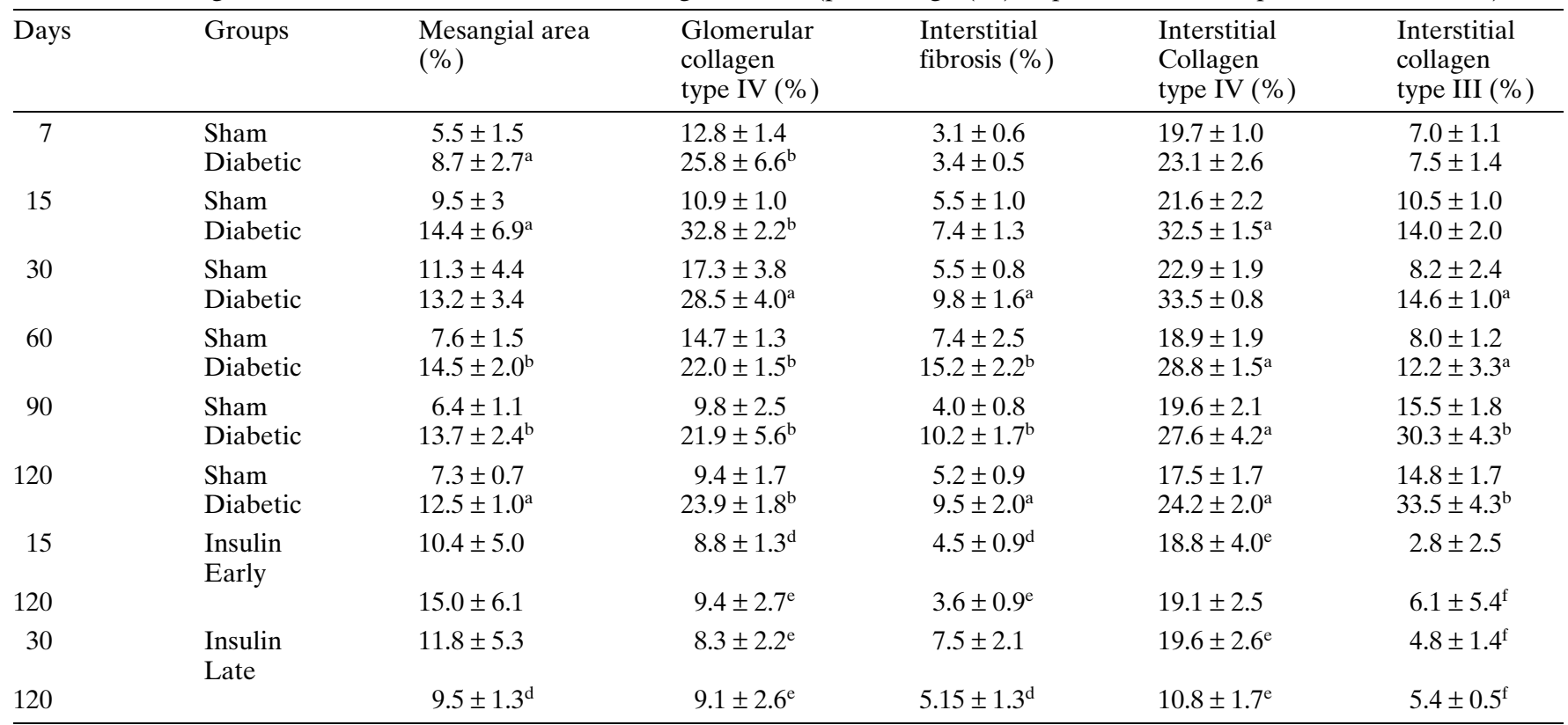

Insulin Early refers to the group of rats where insulin treatment started within 24 hours from onset of diabetes. Insulin Late refers to insulin treatment started 15 days after the onset of diabetes.
${ }^{\mathrm{a}}=p<0.05,{ }^{\mathrm{b}}=p<0.01,{ }^{\mathrm{c}}=p<0.001$ untreated diabetic compared with Sham-treated rat. ${ }^{\mathrm{d}}=p<0.05,{ }^{\mathrm{e}}=p<0.01,{ }^{\mathrm{f}}=$ $p<0.001$ insulin-treated compared with untreated diabetic rats

collagen detected within diabetic rat kidneys (Table 2).

Immunostain of $\alpha$-smooth muscle actin $(\alpha-S M A)$. The detection of immunoreactive $\alpha$-SMA was confined in normal (buffer-injected) young rat kidneys to the vascular media (Fig. 1A). By day 60, some glomerular $\alpha$-SMA was, however, noted in control rats whereas immunostainable $\alpha$-SMA appeared in the interstitium from day 90 onward. By contrast, in diabetic rats, there was a neo-expression of $\alpha$-SMA within mesangial cells during the early time-points. This was noticeable by day 7 and remained raised throughout the experimental time (Table 3, Fig.1B). In diabetic rats, glomerular $\alpha$-SMA was significantly higher than controls at all time-points (Table 3). Early and late insulin treatment decreased and reversed respectively the increased expression of glomerular $\alpha$-SMA. In diabetic rats, $\alpha$-SMA positive cells also appeared in the renal interstitium (Fig. 1C) as early as 7 days after STZ injection and increased steadily over the 120-day experimental period. The immunostain was detected within peritubular capillaries and interstitial peritubular cells (Fig.1C). Early and late insulin treatment significantly reduced the expression of interstitial $\alpha$-SMA (Table 3 ). Some tubular cells of diabetic rats showed immunostain for $\alpha$-SMA (Fig. 1D).

There was a positive correlation between glomerular mesangial volume and the amount of immunoreactive $\alpha$-SMA $(r=0.46, p<0.02)$. Similarly, intersti- 

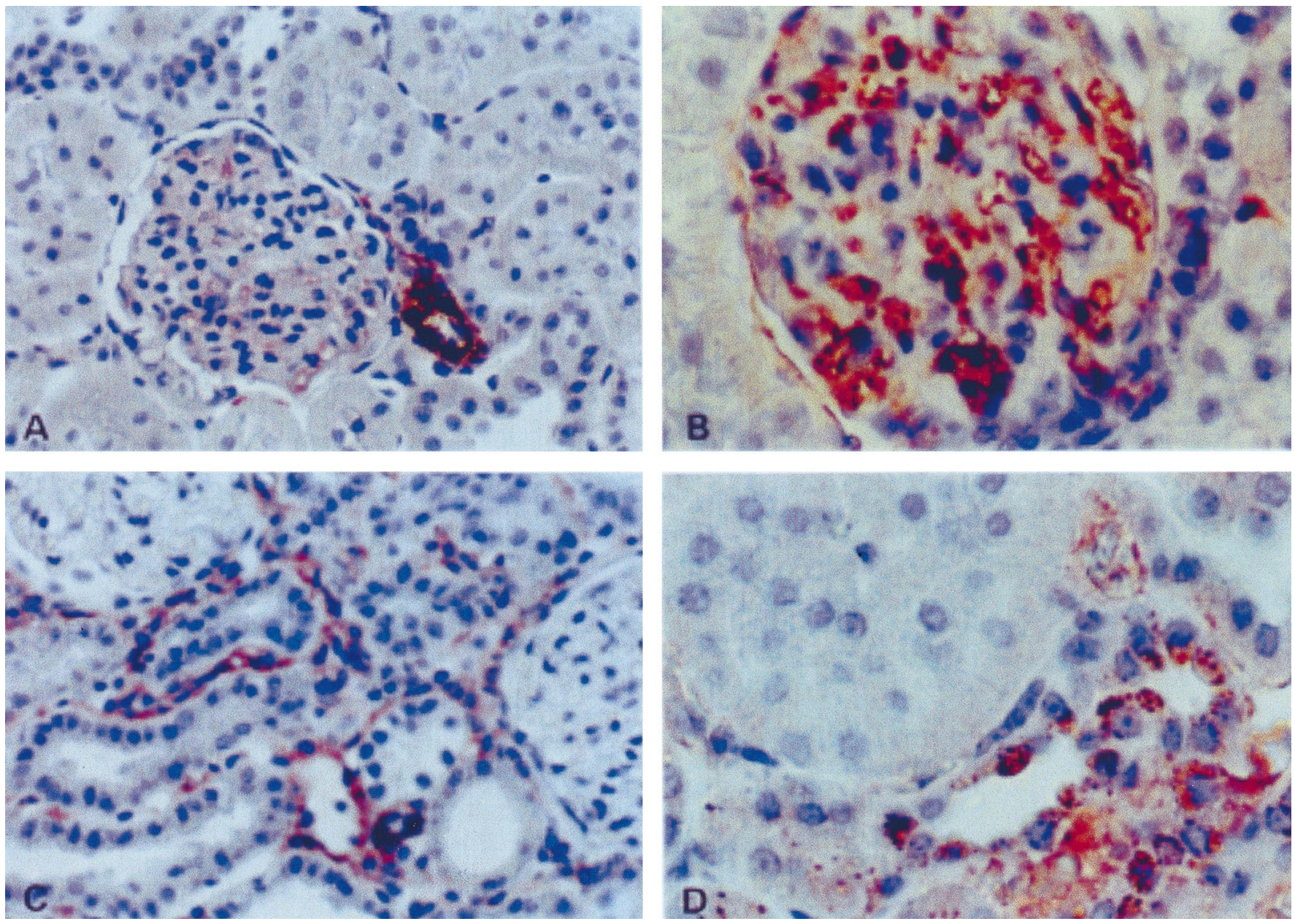

Fig. 1A-D. Photomicrographs of immunostained kidney sections for $\alpha$-SMA. A Control from buffer-injected rat showing staining confined to vascular wall $(\times 200)$. B Untreated diabetic rat (day 15) showing glomerular immunostain $(\times 400)$. C Untreated diabetic rat (day 15) showing peritubular, interstitial, staining $(\times 200)$. D Untreated diabetic rat (day 15$)$ showing tubular staining $(\times 400)$.

tial $\alpha$-SMA correlated positively with the interstitial area $(r=0.51, p<0.002)$.

Immunostain of Vimentin. In normal (buffer-injected) rats, immunoreactive vimentin was detected in the glomerular epithelial and endothelial cells (Fig. 2A). In diabetic rats, there was a significant and transient (most notable on day 15) increase in the glomerular endothelial vimentin immunostain (Fig. 2B). This increase was prevented in rats treated with insulin from the outset (Fig. 2C) (Table 4). Vimentin appeared in peritubular capillaries of the kidneys of diabetic rats peaking on day 15 and remained raised throughout the experimental time (Fig.2D). Other peritubular interstitial cells also stained positively for vimentin in diabetic rats (Fig. 2E). Tubular neoexpression of vimentin was also noted (Fig. 2F).

It was distributed along the basolateral aspects of tubular cells. Finally, in diabetic rats we noted the neoexpression of vimentin within the walls of renal arterioles (Fig. 2D). These changes in vimentin immunostain were considerably blunted by insulin treatment (Fig. 2C).

The rat injected with STZ who did not develop diabetes displayed immunostaining patterns similar to controls; buffer-injected rats.

$m R N A$ expression. Significant changes in $\alpha$-SMA mRNA were detected late (60 days after STZ injection) (Fig.3A). Vimentin mRNA expression (Fig. 4A) was increased from day 7 onwards. This did not, however, reach significance until 60 days after STZ injection. Notably, both vimentin (Fig. 4B) and $\alpha$-SMA mRNAs (Fig. 3B) responded in a similar manner in hyperglycaemic animals treated with insulin. With both immediate and delayed application of insulin there was no change in vimentin or $\alpha$-SMA mRNA expressions when compared with the diabetic untreated rats 15 days after insulin treatment. At 120 days after STZ injection, however, animals treated with immediate and delayed insulin had large reductions in $\alpha$ SMA and vimentin mRNAs (Fig. 3, 4C). With vimentin mRNA, both early and delayed insulin treatment 
Table 3. Quantitative analysis (\% positive point counting) of the immunostains for $\alpha$-SMA

\begin{tabular}{clcc}
\hline Days & Groups & $\begin{array}{c}\text { Glomerular } \\
\alpha \text {-SMA }(\%)\end{array}$ & $\begin{array}{c}\text { Interstitial } \\
\alpha \text {-SMA }(\%)\end{array}$ \\
\hline 7 & Sham & 0 & 0 \\
& Diabetic & $3.1 \pm 0.8$ & $2.1 \pm 0.4$ \\
15 & Sham & 0 & 0 \\
& Diabetic & $11.4 \pm 3.4$ & $2.5 \pm 0.9$ \\
30 & Sham & 0 & 0 \\
& Diabetic & $8.2 \pm 1.8$ & $2.4 \pm 1.3$ \\
60 & Sham & $1.5 \pm 1.1$ & 0 \\
& Diabetic & $10.1 \pm 2.2^{\mathrm{c}}$ & $2.9 \pm 1.2$ \\
90 & Sham & $4.2 \pm 0.8$ & $0.26 \pm 3.9$ \\
& Diabetic & $16 \pm 2.2$ & $2.1 \pm 0.3$ \\
120 & Sham & $2.9 \pm 1.1$ & $0.5 \pm 0.3$ \\
& Diabetic & $9.6 \pm 2.9^{\mathrm{b}}$ & $3.6 \pm 1.5^{\mathrm{b}}$ \\
15 & Insulin & $1.6 \pm 0.6^{\mathrm{f}}$ & $0.5 \pm 0.1^{\mathrm{e}}$ \\
120 & Early & $3.42 \pm 2.9^{\mathrm{e}}$ & $0.3 \pm 0.4^{\mathrm{e}}$ \\
30 & Insulin & $1.48 \pm 0.9^{\mathrm{f}}$ & $1.46 \pm 0.5^{\mathrm{d}}$ \\
120 & Late & $3.64 \pm 3.8^{\mathrm{d}}$ & $1.35 \pm 0.9^{\mathrm{d}}$ \\
\hline
\end{tabular}

Results (Means \pm SD) are expressed as percentage positively stained points. Insulin Early refers to the group of rats where insulin treatment started within 24 hours from onset of diabetes. Insulin Late refers to insulin treatment started 15 days after the onset of diabetes.

${ }^{\mathrm{a}}=p<0.05,{ }^{\mathrm{b}}=p<0.01,{ }^{\mathrm{c}}=p<0.001$ untreated diabetic compared to Sham-treated rat, ${ }^{\mathrm{d}}=p<0.05,{ }^{\mathrm{e}}=p<0.01,{ }^{\mathrm{f}}=$ $p<0.001$ insulin-treated compared to untreated diabetic rats

Table 4. Quantitative analysis (\% positive point counting) of the Vimentin immunostain

\begin{tabular}{clllc}
\hline Days & Groups & $\begin{array}{l}\text { Glomerular } \\
\text { Vimentin } \\
(\%)\end{array}$ & $\begin{array}{l}\text { Vascular } \\
\text { Vimentin } \\
(\%)\end{array}$ & $\begin{array}{l}\text { Tubulo- } \\
\text { interstitial } \\
\text { Vimentin } \\
(\%)\end{array}$ \\
\hline 7 & Sham & $23.2 \pm 7$ & 0 & 0 \\
& Diabetic & $39.1 \pm 10.6$ & $1.6 \pm 0.7$ & $1.6 \pm 0.7$ \\
15 & Sham & $18.2 \pm 3.5$ & 0 & 0 \\
& Diabetic & $52.5 \pm 16.1^{\mathrm{b}}$ & $2.3 \pm 0.5$ & $5.6 \pm 1.5$ \\
30 & Sham & $18.5 \pm 2.9$ & $0.35 \pm 0.1$ & 0 \\
& Diabetic & $16.2 \pm 4$ & $3.1 \pm 0.4$ & $2.04 \pm 0.4$ \\
60 & Sham & $14.5 \pm 1.9$ & $0.7 \pm 0.2$ & 0 \\
& Diabetic & $12.1 \pm 2.6$ & $3 \pm 0.6^{\mathrm{c}}$ & $1.8 \pm 1.5$ \\
90 & Sham & $20.6 \pm 4.3$ & $0.5 \pm 0.2$ & $1 \pm 0.2$ \\
& Diabetic & $26.7 \pm 4.3$ & $3.4 \pm 1.21^{\mathrm{b}}$ & $4 \pm 1.2^{\mathrm{c}}$ \\
120 & Sham & $15.1 \pm 5$ & $0.6 \pm 0.2$ & $0.3 \pm 0.1$ \\
& Diabetic & $13.4 \pm 8.2$ & $3.9 \pm 1^{\mathrm{c}}$ & $2.1 \pm 0.6^{\mathrm{c}}$ \\
15 & Insulin & $14.2 \pm 4.6^{\mathrm{f}}$ & $0.7 \pm 0.2^{\mathrm{f}}$ & $0.8 \pm 0.2^{\mathrm{f}}$ \\
120 & Early & $12.1 \pm 5$ & $1.2 \pm 0.6^{\mathrm{e}}$ & $0.7 \pm 0.4^{\mathrm{e}}$ \\
30 & Insulin & $19.6 \pm 7.5^{\mathrm{e}}$ & $1.08 \pm 0.3^{\mathrm{e}}$ & $0.7 \pm 0.5^{\mathrm{f}}$ \\
120 & Late & $15.3 \pm 3.8$ & $1.35 \pm 0.6^{\mathrm{f}}$ & $0.74 \pm 0.7^{\mathrm{e}}$ \\
\hline R & (Mans &
\end{tabular}

Results (Means \pm SD) are expressed as percentage of positively stained points. Insulin Early refers to the group of rats where insulin treatment started within 24 hours from onset of diabetes. Insulin Late refers to insulin treatment started 15 days after the onset of diabetes.

${ }^{\mathrm{a}}=p<0.05,{ }^{\mathrm{b}}=p<0.01,{ }^{\mathrm{c}}=p<0.001$ untreated diabetic compared to Sham-treated rat, ${ }^{\mathrm{d}}=p<0.05,{ }^{\mathrm{e}}=p<0.01,{ }^{\mathrm{f}}=$ $p<0.001$ insulin-treated compared to untreated diabetic rats returned the expressions to normal. With $\alpha$-SMA mRNA, although decreases were, however, noted these did not quite reach significance $(p=0.09)$ compared with untreated diabetic animals, with both immediate and delayed insulin treated rats still showing significant increases above control animals. Of note, neither cyclophilin mRNA nor $18 \mathrm{~s}$ rRNA were affected by glycaemia (diabetes) or insulin treatment. The ratio of cyclophilin (autoradiograph) to the 18s RNA (from UV gels) remained constant in all experiments indicating that the cyclophilin gene was not regulated by glycaemia or insulin treatment.

\section{Discussion}

The progression of diabetic nephropathy is associated with early adaptive changes and late structural ones. Initially, after the onset of experimental diabetes mellitus, the kidney reacts to hyperglycaemia by glomerular and tubular hypertrophy along with hyperfunction. Glomerular hyperfunction results from the haemodynamic changes taking place within the glomeruli consisting of a predominant afferent arteriolar vasodilatation leading to glomerular hyperperfusion and hyperfiltration [2]. After the early stage of renal hypertrophy and hyperfunction, structural changes take place within the glomeruli, tubules and renal interstitium. Glomerular mesangium expansion precedes mesangio-sclerosis and glomerulo-sclerosis [17]. Tubular vacuolation and lipidosis takes place in poorly controlled diabetes along with progressive interstitial fibrosis $[3,4]$.

In this study, we noted that the early and later stages of experimental diabetic nephropathy are associated with phenotypic changes in renal cells characterised by the expression of $\alpha$-SMA and the intermediate filament protein vimentin. The changes observed in immunostainable $\alpha$-SMA and vimentin were associated with increased transcription of these proteins within the diabetic kidneys. The time scale for the changes in mRNA did not, quite match those of immunostainable proteins. The early changes in protein expression were not matched by changes in transcription as an increase in both mRNA and protein was only evident after 60 days of diabetes. Whether the early changes in immunostainable cytoskeletal pro-

Fig. 2 A-F. Photomicrographs of immunostained kidney sections for vimentin. A Control from buffer-injected rat showing weak glomerular epithelial staining $(\times 200)$. B Untreated diabetic rat (day 15) showing heavier glomerular staining (× 400). C Insulin-treated (Early) diabetic rat (day 15) showing a decrease in glomerular immunostain $(\times 200)$. D Untreated diabetic rat (day 15) showing peritubular capillary staining $(\times 400)$. E Untreated diabetic rat (day 15) showing peritubular cellular staining $(\times 500)$. F Untreated diabetic rat (day 15) showing tubular staining $(\times 400)$ 

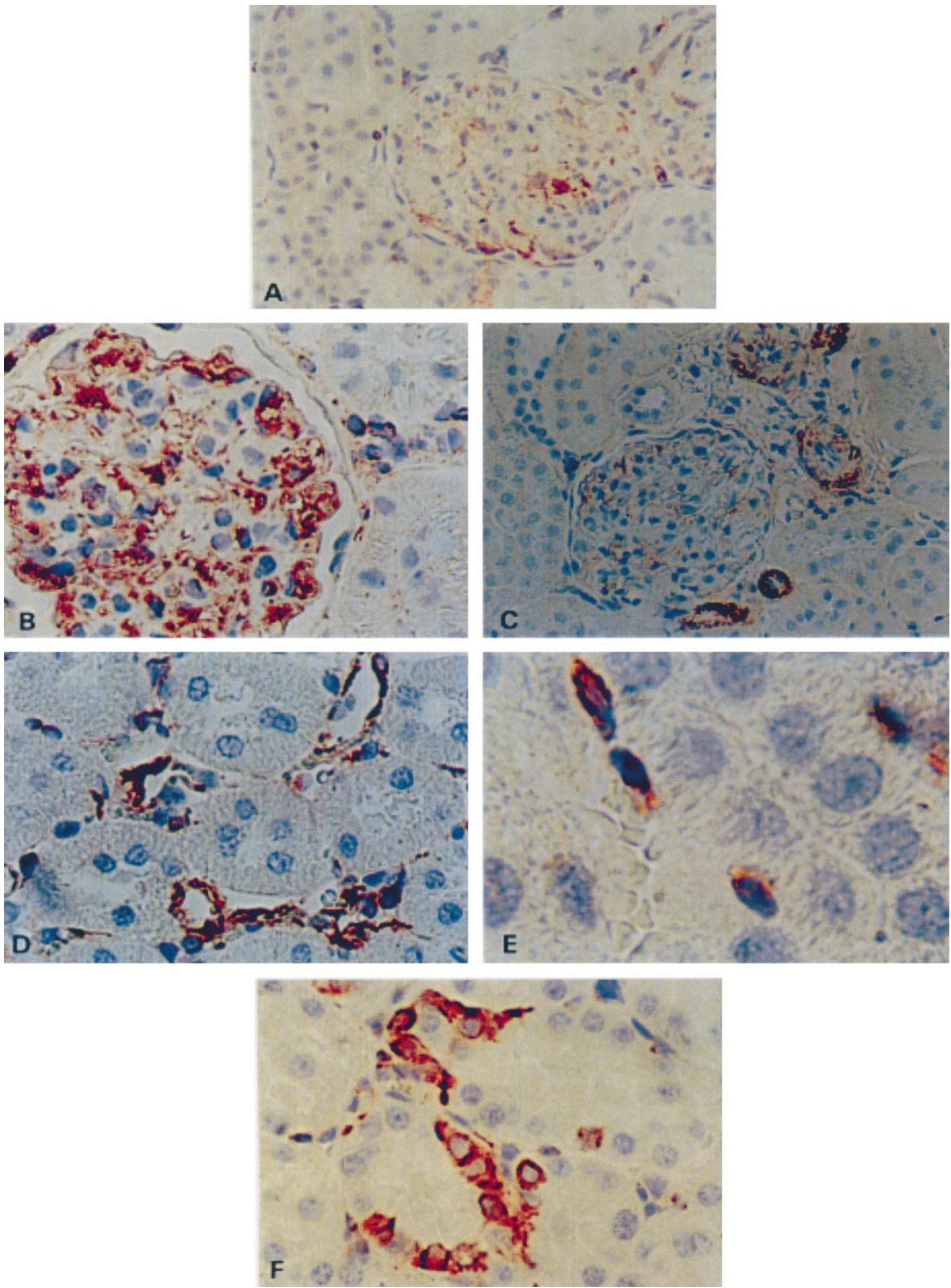

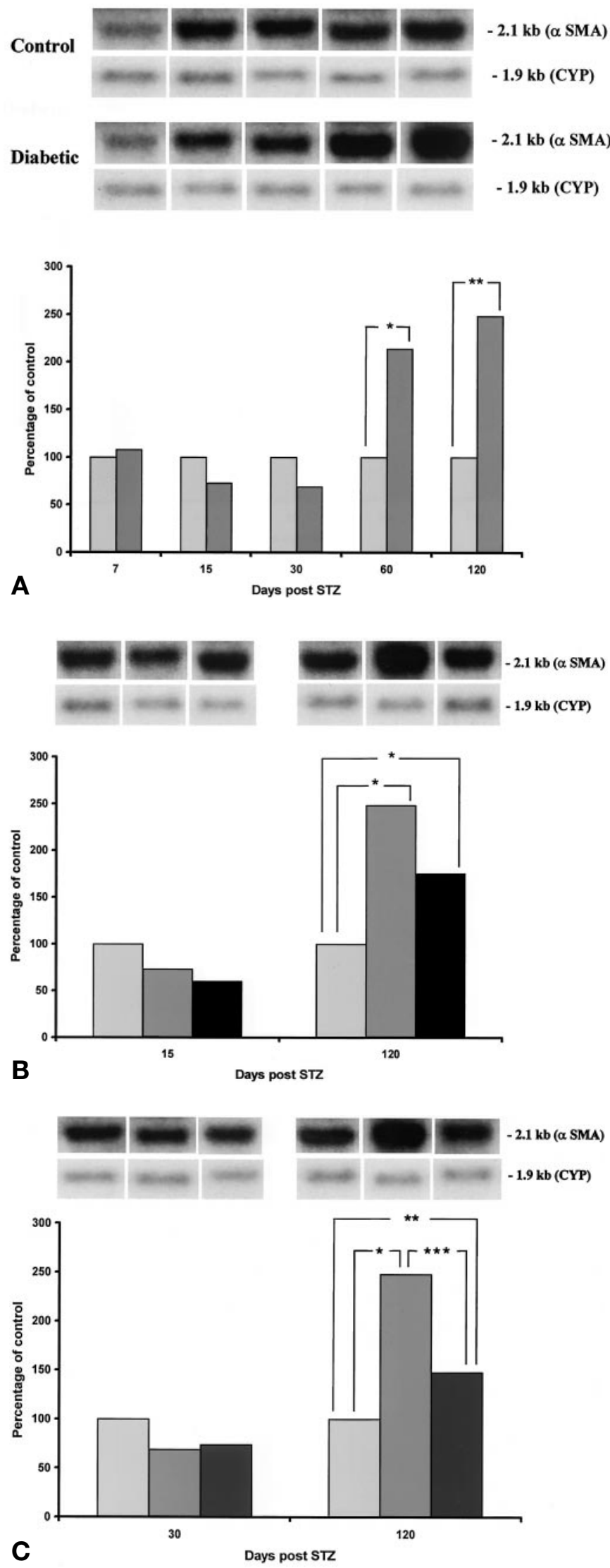

teins were due to changes in synthesis or merely the intracellular redistribution of these proteins is not known. In fibroblasts, changes in phenotype and functional characteristics are associated with the cytoplasmic redistribution of cytoskeletal proteins [18]. This could make them more accessible to immunostain. Other possibilities include changes in translation or breakdown.

For the purpose of this study, we will use the term diabetic nephropathy to refer to the changes taking place in the kidneys of diabetic rats. Clearly, the early changes taking place within the first 30 days are likely to reflect the direct or indirect (glycosylation of proteins) effects of hyperglycaemia on kidney cells. This is supported by our observations of the reversibility of the changes we observed in cellular phenotypes by insulin treatment and the control of the hyperglycaemic state. The reversibility of the changes with insulin also argues against the phenotypic changes being secondary to the effect of streptozotocin on the kidneys. Further, in one rat injected with STZ who did not develop diabetes we failed to observe any histological or immunohistochemical changes as it reacted like the buffer-injected control rats. The changes we observed in our diabetic rats relating to the mesangial expansion and the increased deposition of collagens within the glomeruli and interstitium bear similarities to the advanced stages of diabetic nephropathy in humans where similar "sclerosis/fibrosis" takes place. Further, the increase in immunostainable collagens within the glomeruli and interstitium observed in diabetic rat kidneys support the concept of fibrotic changes taking place within these kidneys. We accept, however, that the structural changes taking place in the kidneys of diabetic rats do not fully reflect those observed in their human counterparts [19]. At worst this experimental model can provide useful information about the effect of sustained hyperglycaemia on renal cells and at best it could give some insights into the pathogenesis of diabetic nephropathy.

Early in the course of diabetes, there was an expression by mesangial cells of $\alpha$-SMA. This is reminiscent of a similar expression of this cytoskeletal protein in experimental and clinical nephropathies associated with mesangial proliferation or activation $[6,20]$. Mesangial $\alpha$-SMA expression was described by others albeit transiently in experimental diabetic

Fig. 3 A-C. Representative autoradiographs and volume density analysis graphs for $\alpha$-SMA mRNA as well as the cyclophilin (CYP) loading control. Data is presented as percentage of mean control values corrected for loading using cyclophilin. A Time course of $\alpha$-SMA mRNA expression over the 120 days time course. B The effect of early insulin therapy (started $24 \mathrm{~h}$ after the induction of diabetes). C The effect of late insulin therapy (started 15 days after the induction of diabetes). $* p<0.05, * * p<0.01, * * * p=0.09$. $\square$ Control $\square$ Diabetic $\square$ Insulin 

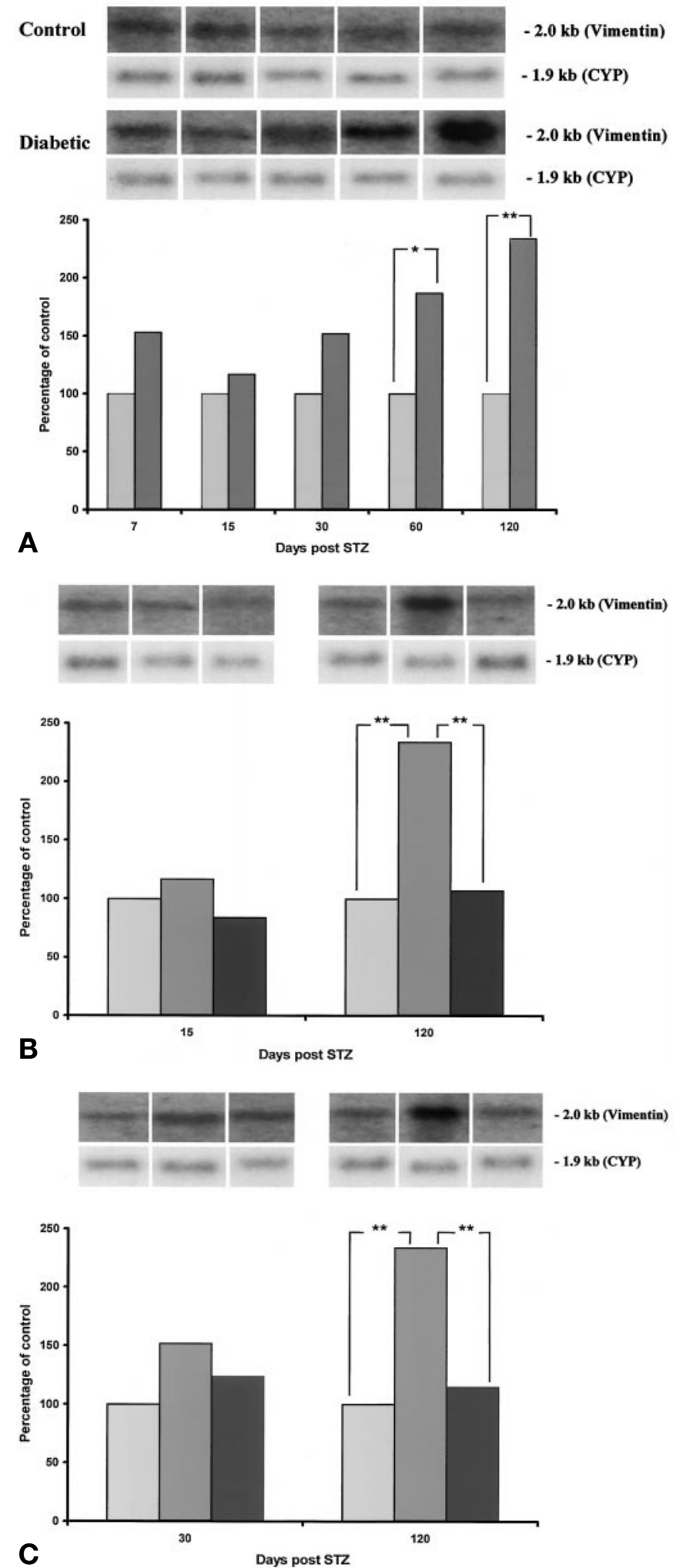

Fig. 4 A-C. Representative autoradiographs and volume density analysis graphs for Vimentin mRNA as well as the cyclophilin (CYP) loading control. Data is presented as percentage of mean control values corrected for loading using cyclophilin. A Time course of Vimentin mRNA expression over the 120 days time course. B The effect of early insulin therapy (started $24 \mathrm{~h}$ after the induction of diabetes). C The effect of late insulin therapy (started 15 days after the induction of diabetes). Early $* p<0.05$, ** $p<0.01$. $\square$ Control $\square$ Diabetic $\square$ Insulin nephropathy [21] and by ourselves in humans with advanced diabetic renal disease [9]. Early hyperglycaemia was also associated in diabetic rats with an up-regulation of glomerular vimentin. In diabetic glomeruli, there was an appreciable increase in endothelial expression of vimentin. The expression of vimentin by glomerular endothelial cells in response to hyperglycaemia could have a role in the haemodynamic response of the glomerulus to hyperglycaemia. This is supported by observations made in vimentin null mice who fail to adapt appropriately to renal injury [22]. Further, in vitro studies suggest a role for vimentin in the response of vascular endothelial cells to hyperglycaemia [23]. Of note, all the changes we described following hyperglycaemia in rats were prevented or reversed by early or late insulin treatment, respectively. This suggests that these changes are directly or indirectly linked to hyperglycaemia.

Tubular changes characterised by vacuolation and lipidosis of cells have been described in uncontrolled hyperglycaemia [3]. The neoexpression of vimentin in some diabetic tubular cells is not unexpected as this intermediate filament protein has been associated in a wide range of tubular injuries [11]. We made a similar observation in the tubules of human diabetic kidneys where tubular atrophy was associated with the expression of vimentin [9]. Notably, we observed that some tubular cells also express $\alpha$-SMA. This has not been previously reported but is not totally unexpected as the acquisition of such a contractile cytoskeletal protein could facilitate the migration of remaining tubular cells along their underlying denuded basement membrane. It is likely that these changes reflect an element of dedifferentiation of tubular cells during the hyperglycaemic injury/repair process. Doubt has, however, been cast on the precise role of vimentin in experimental tubular injury and repair as these processes proceed normally in vimentin null mice [24]. It has been suggested that the expression of vimentin by tubular cells represents their transdifferentiation into a fibroblastic lineage [25]. In such case, these cells with their newly acquired fibroblastic characteristics could contribute to interstitial fibrosis.

Interstitial fibrosis is an important determinant of the progression of diabetic nephropathy [4]. We confirmed in this study observations made in other experimental and clinical nephropathies of an activation of interstitial myofibroblasts [20, 9]. These $\alpha$ SMA positive cells are normally confined to the vascular wall but diffuse into the interstitium during the chronic renal disease thus contributing to interstitial fibrosis [5]. In this study, as in previous ones [20, 9], we noted a close correlation between the number of these cells and the severity of interstitial fibrosis. By contrast, interstitial vimentin appeared predominantly within peritubular capillaries. This pattern was pronounced in the renal medulla and preventable by insulin treatment and the control of hyperglycaemia. 
Damage to peritubular capillaries has recently been reported in experimental renal scarring along with associated changes in the expression of cytoskeletal proteins [26]. Vimentin neoexpression was also noted within the media of the renal arteries and arterioles. This pattern is reminiscent of that observed in the vascular wall of hypertensive rats after subtotal nephrectomy [8]. Diabetic rats were, however, not hypertensive and therefore these changes could reflect injury/proliferation of vascular myocytes in response to hyperglycaemia.

The relevance of the observations described above to the functional or structural changes taking place in diabetes is not known. Whether they reflect the response of renal cells to hyperglycaemic injury or constitute an integral part of the adaptive or reparative renal responses [23] is also not known. Finally, the relevance of these new cellular phenotypes to the development of mesangiosclerosis and interstitial fibrosis is only speculative. Suffice to say that insulin treatment which attenuated the expression of the cytoskeletal proteins also minimised the expansion of the extracellular matrix within the glomeruli and interstitium of diabetic rat kidneys.

Acknowledgements. The authors are grateful to the British Diabetic Association for its support (grant no: RD95/0001082) and the Sheffield Kidney Research Foundation. We would also like to thank Dr. C. Grupp (Georg-August University, Goettingen, Germany) and Dr. Herrmann (German Cancer Research Centre Cellbiology, Heidelberg, Germany) for kindly supplying cDNA sequences for SMA and Vimentin and Dr DJ Bergsma (SmithKline \& Beecham, King of Prussia, Pa., USA) for supplying us with the cyclophilin probe.

\section{References}

1. Breyer JA (1992) Diabetic nephropathy in insulin-dependent patients. Am J Kidney Dis 20: 533-547

2. Hostetter TH, Rennke HG, Brenner BM (1988) The case for intrarenal hypertension in the initiation and progression of diabetic and other glomerulopathies. Am J Med 318: $140-145$

3. Rasch R (1988) Non-glomerular lesions in the diabetic kidney. Nephrology (Proceedings of the Xth International Congress of Nephrology) I: 744-760 p

4. Ziyadeh FN, Goldfarb S (1991) The renal tubulointerstitium in diabetes mellitus. Kidney Int 39: 464-475

5. El Nahas AM, Muchaneta-Kubara EC, Zhang G, Adam A, Goumenos D (1996) Phenotypic changes in the pathogenesis of renal scarring. Kidney Int 49 [Suppl 54]:S23-S27

6. Johnson RJ, Ida H, Alpers C et al. (1991) Expression of smooth muscle cell phenotype by rat mesangial cells in immune complex nephritis: $\alpha$-smooth muscle actin as a marker of mesangial cell proliferation. J Clin Invest 87: 847-858

7. El Nahas AM, Muchaneta-Kubara EC, Tamimi N, Goumenos D (1999) Glomerulosclerosis: The role of interstitial myofibroblasts in its pathogenesis. Curr Top in Pathol 93: 167-172

8. Muchaneta-Kubara EC, El Nahas AM (1997) Myofibroblast phenotypes expression in experimental renal scarring. Nephrol Dial Transplant 12: 904-915
9. Essawy M, Soylemezoglu O, Muchaneta-Kubara EC, Shortland J, Brown CB, El Nahas AM (1997) Myofibroblasts and the progression of diabetic nephropathy. Nephrol Dial Transplant 12: 43-50

10. Skalli O, Ropraz P, Trzeciak A, Benzonana G, Gillensen D, Gabbiani G (1986) A monoclonal antibody against $\alpha$ smooth muscle actin: a new probe for smooth muscle cell differentiation. J Cell Biol 103: 2787-2796

11. Nouwen EJ, Verstepen WA, Buyssens N, Zhu M-Q, De Broe M (1994) Hyperplasia, hypertrophy and phenotypic alterations in the distal nephron after proximal tubular injury in the rat. Lab Invest 70: 479-493

12. Raij L, Azar S, Keane W (1984) Mesangial immune injury, hypertension, and progressive glomerular damage in Dahl rats. Kidney Int 26: 137-143

13. Tamaki K, Okuda S, Ando T, Iwamoto T, Nakayama M, Fujishima M (1994) TGF- $\beta 1$ in glomerulosclerosis and interstitial fibrosis of adriamycin nephropathy. Kidney Int 45: 525-536

14. Williams MA, Lowrie JI (1987) In: Bach FH, Lock EA (eds) Fixation of tissue for morphometric study. Nephrotoxicity in Experimental Clinical Situations. Part 1. Dordrecht, Nijhoff, pp 141-166

15. McHugh KM, Lessard JL (1988) The nucleotide sequence of a rat vascular smooth muscle alpha-actin cDNA. Nucleic Acids Res 16: 4167

16. Herrmann H, Fouquet B, Franke WW (1989) Expression of intermediate filament proteins during development of Xenopus laevis I. cDNA clones encoding different forms of vimentin. Development 105: 279-298

17. Steffes MW, Osterby R, Chavers B, Mauer M (1989) Mesangial expansion as a central mechanism for loss of kidney function in diabetic patients. Diabetes 38: 1077-1081

18. Desmouliere A, Gabbiani G (1994) Modulation of fibroblastic cytoskeletal features during pathological situations: The role of extracellulare matrix and cytokines. Cell Motil Cytoskeleton 29: 195-203

19. Kempe HP, Engelman K, Gretz N, Hasslacher C (1993) Models of diabetes for studying diabetic nephropathy. In: Gretz N, Strauch M (eds) Experimental and Genetic rat Models of Chronic Renal Failure. Basel, Karger, pp $148-155$

20. Goumenos D, Brown CB, Shortland J, El Nahas AM (1994) Myofibroblasts and the progression of IgA nephropathy. Nephrol Dial Transplant 9: 1418-1425

21. Young BA, Johnson RJ, Alpers CE et al. (1995) Cellular events in the evolution of experimental diabetic nephropathy. Kidney Int 47: 935-944

22. Terzi F, Henrion E, Colucci-Guyon E et al. (1996) Subtotal nephrectomy $(\mathrm{Nx})$ is lethal in vimentin-null mice: Role of endothelin. J Am Soc Nephrol 7: 1574

23. Mandal AK, Lemley-Gillepsie S, Nafz MA, Khamis HJ (1996) Glucose modulates vimentin assembly associated with endothelin production in cultured human endothelial cells. J Am Soc Nephrol 7: 1568

24. Terzi F, Maunoury R, Colucci-Guyon E et al. (1997) Normal tubular regeneration and differentiation of the post-ischemic kidney in mice lacking vimentin. Am J Pathol 150: 1361-1371

25. Strutz F, Caron P, Tomaszewski I, Fumo P, Ziyadeh F, Neilson EG (1994) Transdifferentiation; a new concept in renal fibrogenesis. J Am Soc Nephrol 5: 819

26. Thomas S, Anderson S, Gordon KL, Oyama TT, Shankland SJ, Johnson RJ (1998) Tubulointerstitial disease in aging: Evidence for underlying peritubular capillary damage, a potential role for renal ischemia. J Am Soc Nephrol 9: 231-242 